\title{
Artigo
}

\section{A presença social do livro: cultura material e público juvenil}

The social presence of the book: material Culture and youth audiences

\section{Livia França Salles'}

'Pontifícia Universidade Católica do Rio de Janeiro, Departamento de Comunicação Social,

Rio de Janeiro, RJ, Brasil

\section{RESUMO}

Neste artigo, pretende-se investigar a importância da materialidade do livro para o público juvenil. Por meio de uma investigação qualitativa feita com jovens leitoras, verificamos que o uso do objeto-livro pode refletir também necessidades sociais, como o pertencimento a um grupo. Como ponto de partida teórico, esse artigo traz os conceitos de sociabilidade e identidade próprias ao universo juvenil, além de refletir sobre as características culturais atribuídas a um objeto, sob a teoria da Cultura Material.

Palavras-chave: Livro; Juvenil; Sociabilidade; Cultura Material

\section{ABSTRACT}

This article aims to investigate the importance of the materiality of the book for the youth public. Through a qualitative investigation made with young readers, we found that the use of the book can also reflect social needs, such as belonging to a group. As a theoretical starting point, this article brings the concepts of sociability and identity proper to the juvenile universe, besides reflecting on the cultural characteristics attributed to an object, using the theory of Material Culture.

Keywords: Book; Juvenile; Sociability; Material Culture

\section{INTRODUÇÃO}

Em um dos contos mais conhecidos de Machado de Assis, "O espelho", o personagem Jacobina relembra um episódio curioso de sua juventude. Depois de dias sendo reconhecido e muito bem tratado pelos empregados como Sr. Alferes, 
posição de prestígio da Guarda Nacional, Jacobina descobre-se sozinho na casa de sua tia depois de uma fuga dos escravos. Após dias de solidão e desamparo, só pôde se manter inteiro ao final da estadia por meio de um objeto familiar: a farda de alferes. Jacobina conta que reencontrou sua alma, sua identidade construída aos olhos de outros, ao se ver usando a farda em frente ao espelho.

Essa pequena história pode ser um bom exemplo de como um objeto significa mais do que a sua utilidade prática, estando muitas vezes imbuído de valores e significados. E como Machado tem razão ao afirmar que nossa busca por alguma identidade passa muitas vezes por um objeto inanimado. Neste artigo, pretende-se abordar como um objeto, o livro físico, é significativo para um grupo social específico, os jovens leitores, e como o uso do livro pode ser um reflexo de uma necessidade juvenil: a procura por identidade, que passa por questões de sociabilidade e pertencimento, conforme descrito pelas teorias da Cultura Material e da Cultura Juvenil.

Iremos verificar que o livro impresso possui características sociais, como visibilidade e circularidade em um grupo, que o livro digital ainda não possui ou não the foi atribuído. Logo, este artigo também busca explicar o porquê de o público juvenil ainda ser uma parcela pequena de consumidores de livro eletrônico em comparação aos livros impressos.

\section{METODOLOGIA}

Este artigo é baseado em uma pesquisa qualitativa, feita em 2017, com um grupo de jovens frequentadoras de um clube de leitura na Livraria da Travessa, na zonal sul da cidade do Rio de Janeiro. As perguntas, demonstradas no texto a seguir, foram feitas de forma igual a cada uma das participantes e de forma coletiva. (Por coincidência, o grupo era formado apenas por leitoras, do gênero feminino.) A partir dessa pequena pesquisa, foram analisados e aplicados os conceitos pertinentes à teoria da Cultura 
Material e da Cultura Juvenil, baseados principalmente nas noções dos pesquisadores Daniel Miller e José Machado Pais, respectivamente.

Como forma de delimitar o grupo juvenil de modo etário, de acordo com a lei brasileira, especificamente o Estatuto da Criança e do Adolescente, de 1990, o período da adolescência vai dos 12 aos 18 anos e, em casos excepcionais, o estatuto é aplicável até os 21 anos de idade. A noção de "jovem", conforme veremos a seguir, é um conceito forjado em uma base não muito sólida, funcionando mais como um contraponto a tudo o que não é considerado "adulto" ou "infantil". Contudo, para fins de investigação, o grupo representado pela definição de adolescente é o que compõe a definição de jovem nesta pesquisa.

\section{JUVENTUDE E SOCIABILIDADE}

Para esta pesquisa, é importante estabelecer a relação entre juventude e adolescência ou puberdade. O período da puberdade é reconhecido quase como universal na espécie humana, mas a juventude é, sobretudo, uma categoria social e não uma característica natural do indivíduo. Na modernidade, a juventude tende a ser uma categoria derivada da interpretação sociocultural dos significados da puberdade, este sim, um fenômeno natural e universal que, no entanto, pode adquirir pouca importância conforme a sociedade em que ocorre (GROPPO, 2004, p. 11-12).

Para o pesquisador Luiz Antonio Groppo (2004), a moderna estrutura das faixas etárias, incluindo aí a juventude, é apenas um de muitos outros produtos da modernidade. A juventude, como categoria social, é usada para classificar indivíduos, normatizar comportamentos, definir direitos e deveres. "É uma categoria que opera tanto no âmbito do imaginário social, quanto é um dos elementos 'estruturantes' das redes de sociabilidade" (GROPPO, 2004, p. 12). Groppo ainda compara a estrutura de classes da modernidade com a estrutura de faixas etárias, também fruto dessa modernidade, pois, deste modo, é possível orientar e prever o comportamento social de determinado grupo de forma homogênea. 
Não à toa que o conceito de juventude foi altamente explorado pela indústria cultural no período pós-guerra: "A idade contada sob o rígido critério do tempo absoluto torna-se a melhor forma de reduzir todas as diferenças sociais e individuais reais a um denominador comum e universal" (FORTES apud GROPPO, 2004, p. 17).

Para Edgar Morin (2011, p. 148), a adolescência surge como classe de idade na civilização no século XX. O autor esclarece que, durante os anos 1960,

[...] produziu-se um fenômeno histórico extremamente importante: a autonomização da adolescência. [...]. No nosso caso [em nossa sociedade], a adolescência se desenvolve como um corpo autônomo e se constitui numa cultura. Essa cultura não é apenas o rock, nem apenas agrupamentos em torno de uma música, mas também um modo comum de se vestir, hábitos comuns, quase as mesmas buscas, as mesmas aspirações. [...] Que aspirações são essas? Mais autonomia e mais comunidade. Duas coisas que parecem contraditórias: de um lado, o desejo de ser livre; do outro, o desejo de uma comunidade calorosa (MORIN, 2008).

Percebe-se que há uma aparente contradição entre busca de autenticidade e integração na sociedade por parte dos jovens. Como afirma Morin, na adolescência, a "personalidade" social ainda não está cristalizada. De forma mais simbólica, Morin ao definir cultura, esclarece que uma cultura fornece "pontos de apoio imaginários à vida prática, pontos de apoio práticos à vida imaginária; ela alimenta o ser semirreal, semi-imaginário que cada um secreta no interior de si (sua alma), o ser semirreal, semi-imaginário que cada um secreta no exterior de si e no qual se envolve (sua personalidade)" (MORIN, 2011, p. 5).

É inclusive Edgar Morin quem afirma que há uma necessidade de identidade do público jovem, o que ele denomina de "cultura juvenil", e a sua necessidade de criar laços e estabelecer grupos. A questão do grupo, do vínculo com o outro, é fundamental para a socialização juvenil, pois o grupo é o lugar simbólico onde se realiza a repartição da experiência: “[o grupo] é onde os jovens retiram boa parte de seu sentido de solidariedade e onde encontram o suporte necessário para a complicada negociação coletiva dos valores que giram em torno da construção das identidades singulares" (ROCHA; PEREIRA, 2014, p. 28). 
Esses grupos juvenis, denominados de "instâncias de socialização", ajudam a criar uma realidade social em que indivíduos com a mesma idade pensam e se comportam de modo semelhante. Para Groppo (2014, p. 14), é justamente desta "convivência forçada que nasce a possibilidade destes indivíduos criarem identidades, comportamentos e grupos próprios e alternativos às versões oficiais".

Para os jovens, essas formas de sociabilidade parecem responder às suas necessidades de autonomia, liberdade e trocas afetivas (SOUZA, 2004), conforme estabeleceu Morin (2008; 2011). Berger e Luckmann (apud GROPPO, 2004, p. 13) afirmam que a criação de grupos etários homogêneos acontece em sociedades que possuem uma esfera social "pública" mais elaborada, uma parte da vida social separada das relações de parentesco, ou seja, nestas sociedades exige-se uma "segunda socialização", secundária, que ensina o indivíduo a viver em esferas sociais não organizadas a partir da família ou do parentesco.

Essa "segunda socialização" (o grupo) pode ser entendida como um terceiro espaço de socialização. A partir da visão do sociólogo Eisenstadt, Groppo (2004) aponta três tipos de grupos juvenis no mundo moderno: o primeiro seria a escola; o segundo, os grupos controlados pelos adultos; e o terceiro os grupos juvenis informais, aqueles com espaço de socialização autônoma por parte dos jovens. O espaço então onde os jovens se mostram como gostariam de ser ou ao menos ser vistos. Essa autonomia juvenil está atrelada ao tempo livre dos jovens (tempo fora da obrigação escola-família), um tempo que, "entre os jovens, só tem valor se for útil, promovendo a sociabilidade" (ROCHA; PEREIRA, 2014, p. 23).

O tempo do lazer juvenil deve ser entendido como um tempo e um espaço social. Mais do que diversão ou simples fuga ao tédio, é um tempo dedicado ao escape do controle do universo adulto. É no domínio do lazer, do que fazer com o seu tempo livre das outras obrigações, como a escola, que as culturas juvenis adquirem maior visibilidade e poder próprio de constituição como grupo.

Esse tempo e espaço de lazer é um tempo que almeja ser compartilhado, um "tempo coletivo de que jovens desfrutam, em grupo, é sentido como um tempo 
mais apropriado que qualquer outro à realização dos seus desejos e interesse de marca especificamente mais juvenil" (PAIS, 1993, p. 94). José Machado Pais propõe ainda que as culturas juvenis, como processo de comunicação, produzem signos culturais, que ajudam a afirmar o grupo. Estes signos podem ser divididos em dois tipos: geracionais e grupais.

Os signos juvenis geracionais são os signos comuns aos jovens como coletivo: é a juventude em toda a sua extensão. É o diferencial com a geração anterior, oferecendo um polo agregador de sociabilidades juvenis (PAIS, 1993, p. 103-104).

Como exemplo de signo juvenil geracional, Pais cita a "música". O apreço dos jovens pela música (e por todos os movimentos que ela representa) seria um indicativo de que a música, tal como é configurada pela mídia de massa, é um poder de atração a esses jovens. Entretanto, é preciso ter cuidado para não cair no senso comum de que o interesse na música (de massa) seja exclusiva dos jovens. O aspecto que queremos destacar é que esse interesse deve ser entendido como um tempo maior dedicado pelos jovens ao objeto-valor "música" do que um afeto ou apreciação maior por ela. Esse dado nos ajuda a entender o status dado à literatura juvenil para o público-leitor jovem, por exemplo.

Um outro signo juvenil geracional, para José Machado Pais (1993), seria o tempo livre das instituições escola/trabalho/família -, que seria uma das principais características das culturas juvenis. Conforme dito, nesse tempo livre, os jovens acabam por desenvolver formas genuínas de participação social, "através da efetiva adesão a determinadas atividades e da construção de fachadas reforçativas da coesão de grupo" (PAIS, 1993, p. 94):

[...] os tempos livres podem considerar-se como uma das mais importantes dimensões da vida cotidiana dos jovens no que respeita à definição e compreensão das culturas juvenis, quer o usufruto desses tempos seja considerado como meio de ajustamento ao meio social envolvente, quer como fator de integração geracional. (PAIS, 1993, p. 111). 
O tempo fora do domínio adulto, o "tempo juvenil", seguiu ocupado pelo entretenimento mercadológico da indústria cultural. Transformado em tempo de lazer, a cultura de massa ofereceu ao espírito juvenil o consumo como forma de entretenimento, como os best-sellers da literatura juvenil.

A partir dessas características, é natural supor que os jovens tenham uma afinidade com as novas formas e formatos de entretenimento e lazer, sendo alçados a uma "posição privilegiada a partir de seu 'capital tecnológico"' (ROCHA; PEREIRA, 2014, p. 32). Era de se esperar, portanto, que o público juvenil fosse um grande consumidor de livro digital, mas a tendência das vendas de livros impressos da categoria juvenil não acompanha a versão eletrônica. O que falta então ao livro digital para o público adolescente? Uma pista pode ser uma das características juvenis mais intrínsecas a esse grupo, que é a sociabilidade. O livro impresso parece não ter tido problemas em corresponder a esses anseios juvenis. Há todo um aparato estabelecido de bienais, feiras, noites de autógrafos, clubes do livro, encontros em livrarias em que o livro físico exerce um papel protagonista.

\section{O LIVRO E A CULTURA MATERIAL}

Toda criação humana é produção de cultura, seja ela de qual ordem for. Para o antropólogo Daniel Miller (2002), um dos mais expoentes estudiosos da cultura material, objetos [artefatos] são produtos do desejo humano, logo, regido sob suas regras. Estudar essa lógica nos ajuda a compreender que regras são essas e que tipo de sociedade é capaz de produzi-las. Cultura material, portanto, pode ser entendida como a materialização dela mesma. Podemos afirmar que "os objetos criados por uma civilização tanto constituem quanto refletem a natureza de uma civilização" (DANT, 2006, p. 115-116).

Entender como os objetos estão inseridos em um grupo desvenda o jogo de valores e sentidos que permeia um grupo social. No caso desta pesquisa, o uso do objeto livro nos permite revelar que tipo de classificações e valores são 
importantes para um grupo específico, os jovens. Importante frisar que essa cultura material vai além dos objetos. Talvez fosse mais correto compreendê-la como todo repertório usado pelo homem para a expressão de sentido. Mas a questão material, física, tem um peso importante para esse estudo, pois a fisicalidade parecer exercer um apelo mais imediato, concreto.

Daniel Miller (2002) explica que os objetos tendem a ter um ar de natural, afinal não vemos a sua fabricação. Curioso pois quando pensamos em objetos, pensamos neles como artifícios humanos, coisas fabricadas. A naturalidade sobre a qual Miller fala se deve à circulação dos objetos na sociedade. Com frequência esquecemos que os artefatos são fabricados de acordo com códigos culturais preexistentes. Para Miller (2002, p. 417), os objetos são um meio de socialização, que já possuem um sistema de categorização desde o processo de sua fabricação, e as pessoas se inserem no processo de socialização a partir desses objetos. 0 objeto livro é um exemplo significativo. Historiadores conseguem deduzir que características sociais, culturais e econômicas possuem uma sociedade que consegue produzir um artefato como o livro.

Um dos exemplos mais curiosos é a definição de Roger Chartier (2014, p. 108) para o medo do homem culto na Idade Média. Conta o historiador que desde antes da invenção de Gutenberg, o homem medieval já se preocupava com a quantidade de cópias que circulavam no incipiente mercado e o que elas representavam socialmente. O resultado desse medo é mais bem explicado por Barbier:

[...] os manuscritos em língua vulgar, que se multiplicaram a partir do século XIII, veem seus formatos variar, sobretudo em função de seu conteúdo e da qualidade do proprietário - o formato torna-se um indicador de distinção social: grandes formatos das cópias monumentais executadas para os reis e os personagens mais poderosos, formatos menores para os leitores de menor qualidade (BARBIER apud GONÇALVES, 2010, p. 169).

De acordo com Miller (2002, p. 403), todos os objetos e classificação material evocam distinção social. E, segundo Chartier, o livro sempre foi um objeto dotado de grandes poderes, "tanto desejados quanto temidos", e cita um dos objetos mais 
sagrados e adorados por parte da civilização ocidental: "Por toda a cristandade, a Bíblia era o objeto de usos propiciatórios que pouco tinham a ver com a leitura de seu texto e muito a ver com sua presença em proximidade com o corpo" (CHARTIER, 2014, p. 118-119).

Esse culto ao livro é, na verdade, ao que o livro pode representar, assim como o que o livro impresso representa para os jovens em contraponto ao que o livro digital pode ou deixa de representar.

\section{O LIVRO SEGUNDO O PÚBLICO JUVENIL: PESQUISA QUALITATIVA}

O livro é uma forma esteticamente agradável, uma obra de arte com seu mérito próprio, com uma capa elegante e um design atraente, que é gratificante segurar, abrir e possuir. É também excepcionalmente amigável ao usuário: não há nada mais fácil do que virar as páginas de um livro e ler um texto claro em papel branco. A vista não cansa e podese ir para trás e para frente em com facilidade. Não precisa de bateria, não trava e não quebra se for derrubado (THOMPSON, 2013, p. 344).

Não podemos negar que esse apelo físico do livro impresso é tentador. Mas isso é para a geração descendente de Gutenberg, que não se arrisca em uma das mais controversas invenções editoriais: o livro digital.

Como vimos, o público juvenil é o que teria mais potencial em se interessar pelo livro eletrônico ${ }^{1}$, mas essa conexão não é tão orgânica.

Para ajudar a entender a dinâmica entre jovens e livros impressos e digitais, foi feita uma pesquisa qualitativa com um grupo de leitura juvenil. A pesquisa foi realizada durante o encontro mensal do clube, que atende pelo nome peculiar de \#JovensLeitoresLoucosPorLivrosPraCaramba, claramente uma alusão ao universo digital, hoje dominado pelas hashtags. No dia do encontro,

\footnotetext{
${ }^{1}$ Diferentemente do mercado, a academia já começa a diferenciar os termos digital e eletrônico para livro. Livros digitais são aqueles criados em versões .html, .txt ou .pdf disponíveis para visualização na Internet. Podem ser também cópias digitais de livros impressos, por meio do escaneamento de páginas. Livros eletrônicos são aqueles disponíveis nos formatos epub, mobi, azw e ios, entre outras. Em suma, em formatos comerciais. Para este artigo, eles serão considerados sinônimos: o livro como produto vendido em sua forma digital/eletrônica ou impressa/física. Ver mais em Oddone (2013).
} 
compareceram oito meninas entre 12 e 16 anos, com exceção da mediadora de 21 e de uma participante de 22 anos $^{2}$. Ao serem questionadas sobre o que caracterizava uma literatura juvenil, se é o contexto juvenil na literatura ou a faixa etária de leitores que consomem esta literatura, elas foram categóricas em afirmar que entendem a literatura juvenil como aquela que traz a temática jovem em seus livros. Curioso que, de forma espontânea, as frequentadoras do grupo corroboram com a ideia de que a juventude é mais próxima de uma identidade, ou seja, uma construção cultural e/ou social, do que uma rígida formalização etária.

Foi questionado às jovens leitoras se elas liam ou consumiam livro digital. A resposta foi negativa. Importante frisar que a falta de uso ou de leitura de livro digital não significa que não há leitura de conteúdo digital. Todas as frequentadoras afirmaram ler, com bastante frequência, até fan fictions ${ }^{3}$. Perguntadas sobre o fato de o porquê não consumirem livro digital, foi possível enumerar, de forma pontual, as seguintes respostas:

1. Levar (mobilidade, circulação, visibilidade)

2. Mostrar aos amigos (pertencimento, visibilidade)

3. Colocar na estante (classificação, visibilidade)

4. Possibilidade de objetos anexos (complementariedade)

5. Preço (fator econômico)

6. Autógrafo (exclusividade) ${ }^{4}$

\footnotetext{
2 O encontro ocorreu em 27 de abril de 2017 na Livraria da Travessa (Botafogo) no Rio de Janeiro. Interessante notar que nunca houve a presença de meninos nesse clube; e a participante mais velha assumia a postura dominante no grupo (mais até que a mediadora) e trazia à lembrança algumas vezes o fato de sua idade "avançada" para o grupo. Era, portanto, uma exceção.

${ }^{3}$ Fan fictions ou apenas fanfics são novas narrativas para os personagens de histórias já consagradas em diversas mídias, como livros ou filmes. São enredos inventados por autores amadores, geralmente fãs da história original.

${ }^{4}$ Para a pergunta "Por que vocês não consomem livro digital?", as respostas foram múltiplas e foram ditas basicamente da seguinte forma: "levar o livro; mostrar aos amigos; colocar na estante; o livro impresso é mais barato; dá para assinar o livro; o livro possui brindes como marca-texto".
} 
Percebam que das seis respostas, podemos inferir que três fazem menção mais explícita ao fator visibilidade. "Levar, mostrar", a portabilidade do objeto foi mencionada de relance. Talvez por perceberem que o livro digital seja muito mais adequado à facilidade de transporte do que o livro físico. Mas a segunda fala, que se seguiu logo em sequência, é fundamental para entendermos que tipo de portabilidade é essa. "Mostrar" talvez seja o sentido complementar de "Levar". É poder levar o livro a qualquer lugar desde que este objeto seja visto. É o poder de circulação do objeto.

Já ficar na estante é um lembrete físico e visual de que o livro está ali. É na força da presença, física, do objeto que se apoia o real sentido de "ter o livro", pois é visível e passível de classificação. Mas também é uma referência externa e visível a uma outra pessoa. A questão dos autógrafos também faz referência a um objeto físico. Uma reverência talvez fosse o termo mais exato. Algo que consagra aquele objeto e o transforma em único. É um marcador de exclusividade, uma vez que, por mais apreço que um leitor possa ter por seu livro impresso, ele é apenas mais um na tiragem.

Sobre essa questão, o antropólogo Appadurai (2010, p. 64) contribui ao afirmar que "conforme a tecnologia possibilita a multiplicação de objetos de prestígio, instaura-se um crescente e irônico diálogo entre a necessidade de critérios de autenticidade [...] De uma forma geral, podemos sugerir que [...] a questão da exclusividade dá lugar à questão da autenticidade". E possivelmente passível de ser mostrado a outros, mesmo que esse não seja a razão principal. 0 encontro com o autor, com o conteúdo e com a magia do livro estão representados no objeto físico.

Contudo, apesar de as leitoras terem dito que obter o autógrafo seria importante, o que mais vemos em feiras, bienais e lançamentos de livro, é sim a continuação da cultura do autógrafo, mas que hoje divide espaço com as fotos tiradas com os autores, que não sacraliza nenhum objeto, mas também serve ao 
propósito de "mostrar", tornar a sua lembrança visível a outros, principalmente nas redes sociais.

A possibilidade de outros objetos gerados pelo livro não precisaria estar atrelada ao livro impresso. Mas a associação se dá, provavelmente, devido ao fator físico dos objetos. Esse movimento pode ser explicado pelo conceito do antropólogo Grant McCracken (2003), chamado de Efeito Diderot, em que há objetos que se aproximam por pertencerem a uma mesma categoria cultural. Por exemplo, comprar o livro na capa original, depois com a capa do livro gerada pelo filme ou ainda uma caneca com a representação do livro/filme. Tudo faz parte de uma mesma unidade cultural. Exercem, portanto, a mesma função: eles ajudam a complementar e reforçar o sentido social atrelado àquele objeto.

Nota-se que a visibilidade parece ser um fator importante a este grupo, mas ela não deve ser entendida como um conceito vazio ou superficial. O "tornar visível" torna possível o contato com o outro: o que aqui chamamos de sociabilidade, tão fundamental para os jovens, José Machado Pais chama de natureza identitária: as buscas de si através do outro. Segundo Pais:

De fato, a consciência da identidade individual somente é possível pelo reconhecimento do outro. Muito do que está fora de nós pertence à essência do eu que se revela no outro. [...] A procura de contato é também uma busca de si, uma vez que as identidades individuais se constituem como resultado de experiências individuais, embora surgidas de ritualizações próprias de identidades coletivas (PAIS, 2006, p. 18).

Em relação ao preço do livro, quem trabalha nesse ramo já ouviu o argumento de que livro digital não vende pois o preço não é atraente se comparado com o livro impresso. Pode ser verdade, mas não parece ser o suficiente para explicar o limite de vendas do livro digital ou ainda um aparente desinteresse por determinada faixa de público. O que nos parece mais evidente é que as classificações simbólicas referentes ao livro impresso, tais como visibilidade, circularidade e exclusividade ainda não pertencem ao universo do livro digital. 


\section{CONSIDERAÇÕES FINAIS}

Com a chegada do livro digital, estudiosos e profissionais do livro apontaram suas expectativas de que seria um mercado facilmente explorado pelos adolescentes, afinal a proximidade com a linguagem digital, como baixar arquivos, pesquisar online, era bem dominada por eles. Mas o que não poderiam prever é que talvez careça ao livro eletrônico uma das características mais buscadas pelos jovens: sociabilidade. Aqui, compreendida como resultado de uma necessidade de pertencimento, que é a incessante busca por uma identidade, um encontro com o "eu".

O livro impresso circula e é visível, ou seja, tem presença social. Ainda muito inerente à sua materialidade, o impresso circula no grupo de modo mais dinâmico do que o livro digital. Como bem afirma Thompson, o livro é um objeto social, pois pode ser compartilhado com outros, tomado emprestado, e devolvido, acrescentado a uma coleção, exposto em uma prateleira, "acalentado pelo proprietário como uma preciosidade e visto como um sinal de quem ele é e o que é importante para ele, um sinal de identidade de seu próprio proprietário" (THOMPSON, 2013, p. 345).

O livro impresso traz identidade ao seu dono, pois o seu poder de circulação e visibilidade permite deduzir onde o seu leitor pertence ou não pertence. Sob os olhos da cultura material, seria correto dizer que os objetos legitimam, afinal “o que é consumido não pode ser tratado apenas pelo aspecto funcional mas sim como parte de um processo cultural, que define um status social e uma identidade individual" (DANT, 2006, p. 14). Essa relação tem caráter classificatório e, internamente, agregador. A função do livro aqui é permitir que seu dono se reconheça no grupo e marque uma distinção entre outros grupos.

Já Thompson ainda sugere que o livro eletrônico não consegue reproduzir a materialidade do livro, pois é conteúdo puro. Ou seja, falta ao digital a legitimidade física do livro, que no sentido simbólico se traduz em valores sociais já estabelecidos e aceitos dentro de um grupo. Aqui, o livro se transforma na 
mediação entre a expectativa do pertencimento e o real reconhecimento dentro de um grupo.

Voltando ao Jacobina, do conto de Machado de Assis, deixamos a longa mas poética passagem do narrador sobre estar no mundo e sua relação com os objetos:

Cada criatura humana traz duas almas consigo: uma que olha de dentro para fora, outra que olha de fora para dentro [...]. A alma exterior pode ser um espírito, um fluido, um homem, muitos homens, um objeto, uma operação. Há casos, por exemplo, em que um simples botão de camisa é a alma exterior de uma pessoa; e assim também a polca, o voltarete, um livro, uma máquina, um par de botas, uma cavatina, um tambor. Está claro que o ofício dessa segunda alma é transmitir a vida, como a primeira; as duas completam o homem, que é, metafisicamente falando, uma laranja. Quem perde uma das metades, perde naturalmente metade da existência; e casos há, não raros, em que a perda da alma exterior implica a da existência inteira.

\section{REFERÊNCIAS}

APPADURAI, Arjun. A vida social das coisas. Niterói: Editora da Universidade Federal Fluminense, 2010.

CHARTIER, Roger. A mão do autor e a mente do editor. São Paulo: Unesp, 2014.

DANT, Tim. Materiality and society. British Journal of Sociology, v. 57, n. 2, p. 289-308, 2006. Disponível em: http://core.ac.uk/download/pdf/71307.pdf. Acesso em: 24 jun. 2018.

GONÇALVES, Márcio Souza. Os meios, seus usos, sua materialidade: a comunicação e sua epistemologia. Revista Famecos, Porto Alegre, v. 17, n. 3, p. 163-172, 2010.

GROPPO, Luiz Antônio. Dialética das juventudes modernas e contemporâneas. Revista de Educação do Cogeime, Belo Horizonte, ano 13, n. 25, p. 9-22, 2004.

MACHADO DE ASSIS. O espelho. In: Papéis avulsos. São Paulo: Companhia das Letras, 2011.

MCCRACKEN, Grant. Cultura \& Consumo. Rio de Janeiro: Mauad, 2003.

MILLER, Daniel. Artifacts and the meaning of things. In: INGOLD, T. (ed.). Companion Encyclopedia of Anthropology. Londres: Routledge, 2002. p. 396-419. 
MILLER, Daniel. Consumo como cultura material. Horizontes Antropológicos, Porto Alegre, ano 13, n. 28, p. 33-63, jul./dez., 2007.

MORIN, Edgar. 1968-2008: o mundo que eu vi e vivi. Conferência. In: Fronteiras do Pensamento. Porto Alegre, 2008. Disponível em:

https://www.fronteiras.com/noticias/artigo-edgar-morin-1968-2008-o-mundo-que-eu-vie-vivi. Acesso em: 23 maio 2019.

MORIN, Edgar. Cultura de massas do século XX, vol. 1: neurose. Rio de Janeiro: Forense Universitária, 2011.

ODDONE, Nanci. A ciência e o livro eletrônico: reinventando a comunicação científica. Rio de Janeiro, 2013.

PAIS, José Machado. Culturas juvenis. Lisboa: INCM, 1993.

PAIS, José Machado. Buscas de si: expressividades e identidades juvenis. In: ALMEIDA, Maria Isabel; EUGENIO, Fernanda (Orgs.). Culturas jovens: novos mapas do afeto. Rio de Janeiro: Jorge Zahar Editor, 2006.

ROCHA, Everardo; PEREIRA, Claudia. Sociabilidade e novas tecnologias: os significados do consumo entre os jovens. In: ROCHA, Everardo; PEREIRA, Claudia; BARROS, C. (Orgs.). Cultura e experiência midiática. Rio de Janeiro: Mauad; Ed. PUC-Rio, 2014.

SOUSA, N.; BRENAND, E. Ser/estar junto juvenil na contemporaneidade: um olhar de Bauman e Maffesoli. Comunicação, Mídia e Consumo, São Paulo, v. 9, n. 24, p. 245-264, 2012.

THOMPSON, J. B. Mercadores de cultura: o mercado editorial no século XXI. São Paulo: Unesp, 2013.

\section{Livia França Salles \\ Mestre em Comunicação \\ lifsalles@gmail.com}

